\title{
Механизм фазового перехода полупроводник-металл в тонких пленках состава $\mathrm{Sm}_{1-x} \mathbf{G d}_{x} \mathrm{~S}$
}

\author{
() В.В. Каминский, С.М. Соловьев, Г.Д. Хавров, Н.В. Шаренкова \\ Физико-технический институт им. А.Ф. Иофрфе Российской академии наук, \\ 194021 Санкт-Петербург, Россия \\ E-mail: vladimir.kaminski@mail.ioffe.ru
}

(Получена 11 апреля 2017г. Принята к печати 19 апреля 2017г.)

\begin{abstract}
Исследовано влияние концентрации гадолиния на фазовый переход полупроводник-металл в тонких поликристаллических пленках состава $\mathrm{Sm}_{1-x} \mathrm{Gd}_{x} \mathrm{~S}$, полученных методом взрывного испарения порошка в вакууме. Показано, что основным фактором физического механизма фазового перехода является сжатие материала пленки и что пленки сохраняют свои полупроводниковые свойства лишь до концентрации гадолиния $x=0.12$.
\end{abstract}

DOI: $10.21883 /$ FTP.2018.01.45317.8606

\section{1. Введение}

Интерес к тонким пленкам на основе твердых растворов моносульфидов самария и гадолиния $\left(\mathrm{Sm}_{1-x} \mathrm{Gd}_{x} \mathrm{~S}\right)$ возобновился в последнее время из-за их применения в качестве материала для изготовления полупроводниковых тензорезисторов [1,2]. Известно, что в объемных образцах твердых растворов составов $\mathrm{Sm}_{1-x} \mathrm{Gd}_{x} \mathrm{~S}$ при критической концентрации гадолиния $x=0.15$ происходит скачкообразный изоструктурный фазовый переход первого рода из полупроводникового состояния в металлическое [3]. Предполагаемым механизмом возникновения такого перехода является сжатие за счет уменьшения параметра кристаллической решетки из-за замены части ионов $\mathrm{Sm}^{2+}$ с ионным радиусом $1.14 \AA$ на более мелкие ионы $\mathrm{Gd}^{3+}$ с радиусом $0.97 \AA$ в твердом растворе замещения. Этот механизм получил название „химического коллапса“ [3]. Однако этот механизм носит скорее гипотетический характер. В настоящей работе нами сделана попытка проверить эту гипотезу экспериментально.

\section{2. Методика эксперимента}

Известно, что в тонких поликристаллических пленках $\mathrm{SmS}$, полученных взрывным напылением [4], материал пленки находится в сжатом состоянии, что выражается в уменьшении параметра кристаллической решетки материала пленки по сравнению с объемным образцом SmS [5]. Такое сжатие происходит за счет сил поверхностного натяжения, возникающих в каплях конденсата при осаждении $\mathrm{SmS}$ на подложку. При этом внутри капель развивается давление

$$
P=4 \sigma / L
$$

где $\sigma-$ коэффициент поверхностного натяжения, $L-$ диаметр капли. Если это так, то критическое значение $x$ для фазового перехода полупроводник-металл в
$\mathrm{Sm}_{1-x} \mathrm{Gd}_{x} \mathrm{~S}$ должно уменьшиться в пленках по сравнению с объемными образцами из-за возникновения дополнительного сжатия материала, возникающего при изготовлении пленки. Эксперимент сводился к сравнению критических значений $x$ в пленках и объемных образцах.

Нами были получены пленки твердого раствора $\mathrm{Sm}_{1-x} \mathrm{Gd}_{x} \mathrm{~S}$. Пленки напылялись методом взрывного (дискретного) испарения в вакууме порошка соответствующего состава: $x=0 ; 0.12 ; 0.15 ; 0.50,1$ при температуре подложки $400^{\circ} \mathrm{C}$ и $x=0 ; 0.095 ; 0.189 ; 0.33 ; 0.5$; 1 при температуре подложки $450^{\circ} \mathrm{C}$. Толщины пленок составляли $\sim 0.5$ мкм.

\section{3. Экспериментальные результаты и их обсуждение}

Предварительно проведенные эксперименты показали, что состав порошка передается пленке с достаточной точностью. В табл. 1 приведены результаты этих экспериментов. Для определения состава образцов применялся рентгеноспектральный флюоресцентный анализ (РФСА) по методике, приспособленной для анализа элементов с близкими атомными номерами. В качестве эталонов использовались пленки $\mathrm{SmS}$ известной толщины $\sim 0.5$ мкм. Редкоземельные элементы (Р3Э) определялись по $L_{\alpha}$-спектрам, а сера - по $K_{\alpha}$ спектрам. РСФА проводился по аппаратуре VRA-2 фирмы Карл Цейс.

Некоторое отличие результатов анализа от исходных данных носит случайный характер, и его следует отнести за счет неравномерности распределения примесно-

Таблица 1. Сравнение состава шихты и полученной из нее пленки

\begin{tabular}{c|c|c}
\hline Состав & $x$ по закладке & $x$ по РСФА в пленке \\
\hline $\operatorname{Sm}_{1-x} \mathrm{Gd}_{x} \mathrm{~S}$ & 0.1 & 0.11 \\
& 0.2 & 0.18
\end{tabular}


го РЗЭ по объему матрицы из $\mathrm{SmS}$ в исходном веществе, а также за счет погрешности анализа $(\leqslant 10 \%)$.

На рис. 1 приведены результаты проведенного рентгеноструктурного анализа полученных пленок $\mathrm{Sm}_{1-x} \mathrm{Gd}_{x} \mathrm{~S}$ (кривые 2 и 3) и объемных образцов (кривая 1 [3]). На кривой 2 мы наблюдаем снижение концентрации гадолиния, приводящей к фазовому переходу в металлическое состояние в пленках, по сравнению с объемными образцами на 20\%: от $x=0.15$ до $x=0.12$.

Проведенный анализ этих данных позволяет провести количественную оценку полученных результатов. Более удобна для анализа кривая 2. Согласно [5], для $\mathrm{SmS}$ $\sigma=2.1 \mathrm{H} / \mathrm{M}$, и поэтому величина давления, развиваемого силой поверхностного натяжения, может быть вычислена, если известен размер капли. Согласно [6], в тонких пленках $\mathrm{SmS}$ размер капель равен размеру областей когерентного рассеяния рентгеновского излучения (ОКР). Величина ОКР была рассчитана из дифрактограмм согласно формуле Селякова-Шерера, аналогично тому,

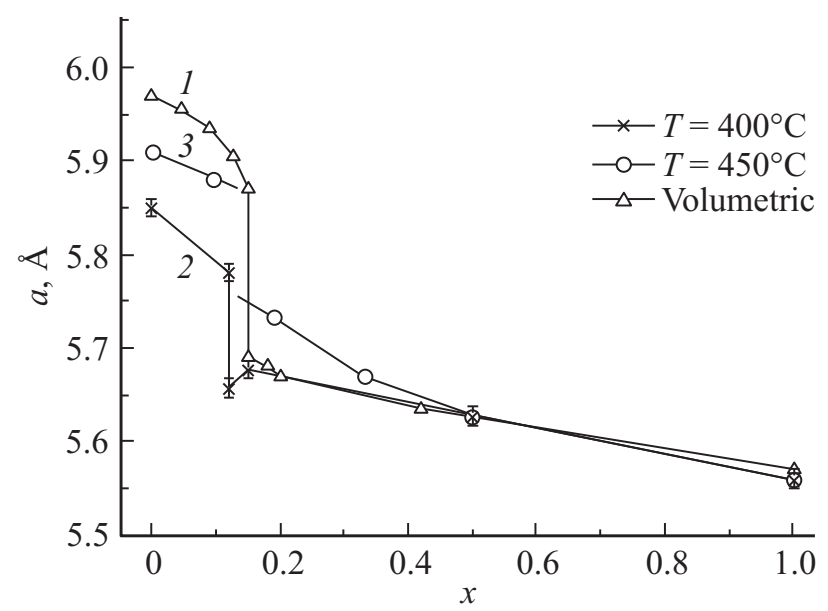

Рис. 1. Зависимость параметров решетки объемных образцов $\mathrm{Sm}_{1-x} \mathrm{Gd}_{x} \mathrm{~S}(1)$ и тонких пленок (2) от состава.

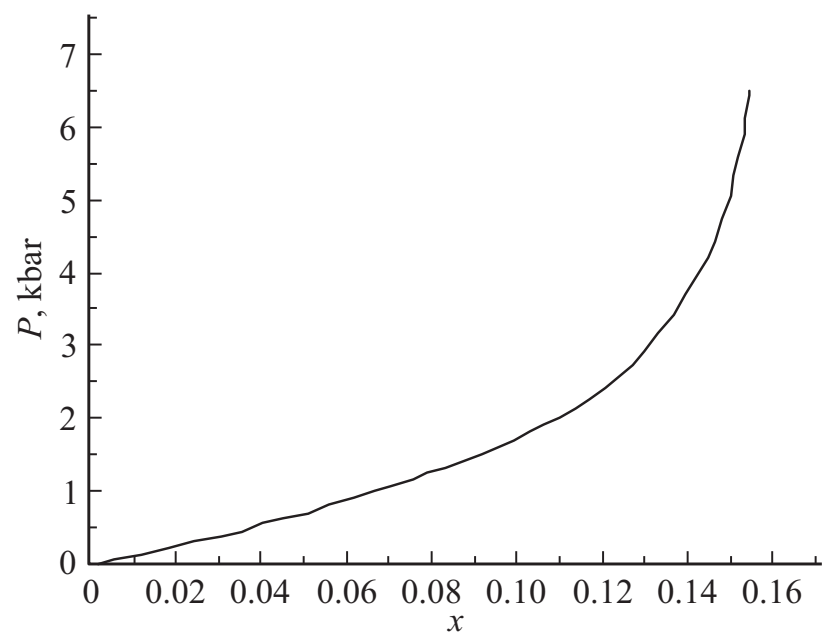

Рис. 2. Зависимость давления, развиваемого в твердых растворах $\mathrm{Sm}_{1-x} \mathrm{Gd}_{x} \mathrm{~S}$, от количества ионов гадолиния.
Таблица 2. Результаты расчета зависимости эффективного давления, развиваемого в тонких пленках $\mathrm{Sm}_{1-x} \mathrm{Gd}_{x} \mathrm{~S}$, от состава

\begin{tabular}{c|c|c|c|c|c}
\hline № & \multicolumn{1}{|c|}{$x$} & OKP, $\AA$ & $P_{\sigma}$, Kбар & $P_{\mathrm{Gd}}, \mathrm{K}$ бap & $P_{\text {eff }}=P_{\mathrm{Gd}}+P_{\sigma}$ \\
\hline 1 & 0 & 307 & 2.74 & 0 & 2.74 \\
2 & 0.12 & 205 & 4.10 & 2.4 & 6.5 \\
3 & 0.12 & 136 & 6.20 & 2.4 & 8.6 \\
4 & 0.5 & 118 & 7.12 & $>6.5$ & $>13.6$
\end{tabular}

как это делалось нами в [7]. В табл. 2 представлены полученные результаты для ОКР, результаты расчета величин давления, рассчитанных по формуле $(1), P_{\sigma}$, а также результаты, полученные нами из зависимости давления, развиваемого включением различного количества ионов гадолиния, $P_{\mathrm{Gd}}$, в твердых растворах $\mathrm{Sm}_{1-x} \mathrm{Gd}_{x} \mathrm{~S}$ (см. рис. 2). Последняя получена из данных работы [8].

Из результатов, представленных в табл. 2, следует, что при $x=0$ и 0.12 (строки 1 и 2) давление $P_{\text {eff }} \leqslant 6.5$ Кбар и вещество находится в полупроводниковом состоянии (фазовый переход полупроводник-металл в $\mathrm{SmS}$ происходит при $P=6.5-8$ Кбар [9]). При $x=0.12$ и 0.5 (строки 3 и 4) давление $P_{\text {eff }} \geqslant 8.6$ Кбар, что соответствует металлической фазе $\mathrm{SmS}$. Составы с $x=0.12$ (строки 2 и 3 ) соответствуют критическому значению $x$ для фазового перехода полупроводник-металл. Аналогичные результаты могут быть получены для кривой 3 рис. 1 . Однако, они представляют меньший интерес, так как в случае напыления пленок при $T=450^{\circ} \mathrm{C}$ нам не удалось попасть по значению х в точку фазового перехода.

\section{4. Заключение}

Из полученных результатов можно сделать вывод, что фазовый переход в твердых растворах $\mathrm{SM}_{1-x} \mathrm{Gd}_{x} \mathrm{~S}$ действительно происходит за счет механического сжатия материала из-за „химического коллапса“. Практически важным выводом является то, что тонкие поликристаллические пленки $\mathrm{SM}_{1-x} \mathrm{Gd}_{x} \mathrm{~S}$ сохраняют свои полупроводниковые свойства лишь до концентрации $x=0.12$. Это важно при изготовлении на основе рассматриваемых твердых растворов полупроводниковых тензорезисторов.

\section{Список литературы}

[1] В.А. Иванов, В.В. Каминский, Н.Н. Степанов. Научное приборостроение, 24, 77 (2014).

[2] В.В. Каминский, С.М. Соловьев, А.В. Голубков, Н.М. Володин. Патент на полезную модель № 110472. Приоритет от 10.05.2011.

[3] И.А. Смирнов, В.С. Оскотский. УФН, 124, 241 (1978).

[4] В.В. Каминский, Н.М. Володин, С.М. Соловьев, Ю.Н. Мишин, Н.В. Шаренкова. Вестн. „НПО им. С.А. Лавочкина“, № 2, 26 (2013). 
[5] С.В. Погарев, И.Н. Куликова, Е.В. Гончарова, М.Н. Романова, Л.Д. Финкельштейн, Н.Н. Ефремова, Т.Б. Жукова, К. Гарцман, И.А. Смирнов. ФТТ, 23, 434 (1981).

[6] Н.В. Шаренкова, В.В. Каминский, С.Н. Петров. ЖТФ, 81, 144 (2011).

[7] Н.В. Шаренкова, В.В. Каминский, А.В. Голубков, Л.Н. Васильев, Г.А. Каменская. ФТТ, 47, 598 (2005).

[8] A. Jayaraman, P.D. Dernier, L.D. Longinotti. High Temp., High Press., 7, 1 (1975).

[9] С.И. Гребинский, В.В. Каминский, А.В. Рябов, Н.Н. Степанов Физика и техника высоких давлений, 16, 22 (1984).

Редактор Г.А. Оганесян

\section{Mechanism of Semiconductor-Metal \\ Phase Transition in Thin Films \\ of $\mathbf{S m}_{1-x} \mathbf{G d}_{x} \mathbf{S}$ Composition}

V.V. Kaminsky, S.M. Soloviev, G.D. Khavrov,

N.V. Sharenkova

loffe Institute,

194021 St. Petersburg, Russia

Abstract The effect of gadolinium concentration on the semiconductor-metal phase transition in thin polycrystalline films of $\mathrm{Sm}_{1-x} \mathrm{Gd}_{x} \mathrm{~S}$ composition, obtained by explosive evaporation of a powder in a vacuum, is investigated. It is shown that the main factor of the physical mechanism of the phase transition is the compression of the film material and that the films retain their semiconductor properties only to the gadolinium concentration $x=0.12$. 